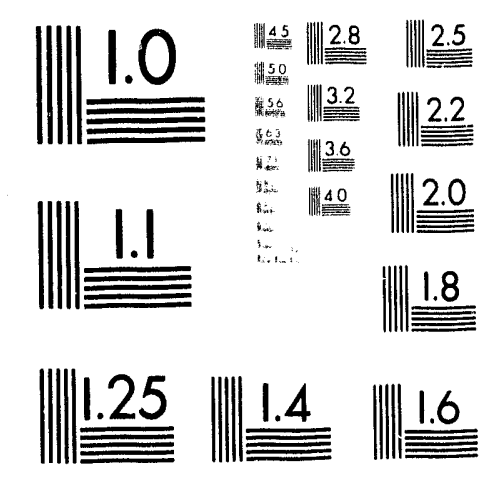



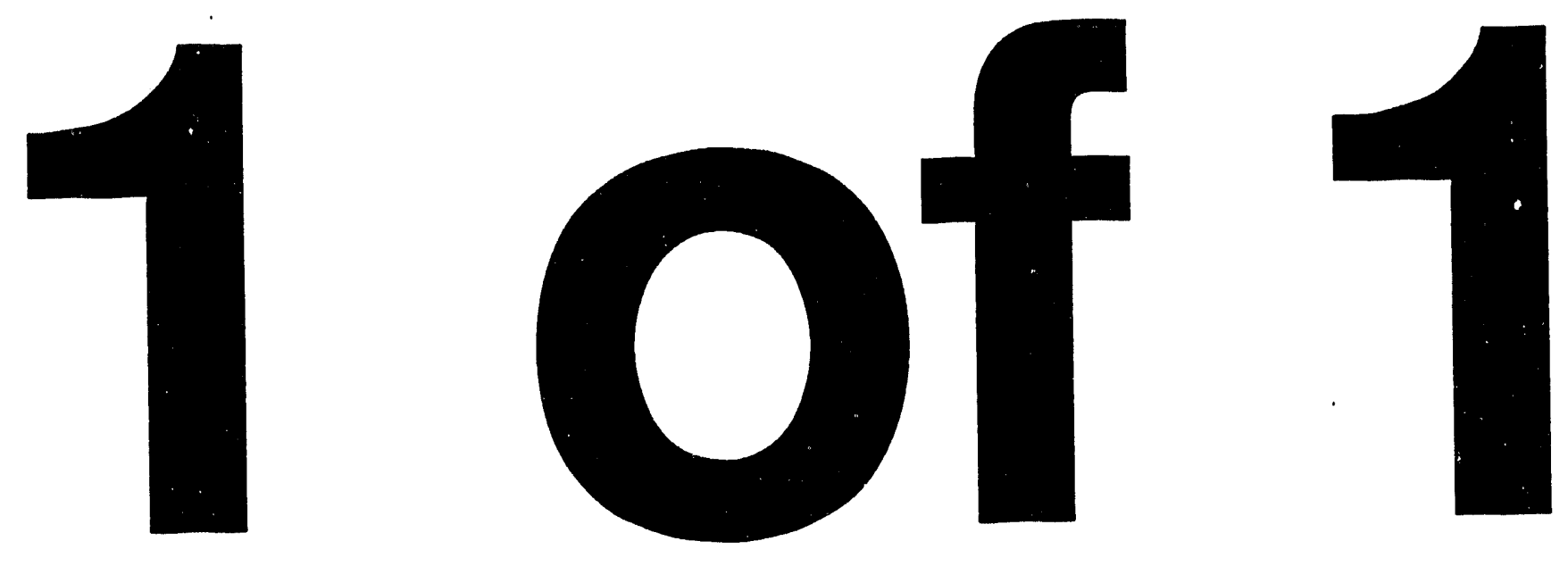


\title{
Deep Seismic Survey Extending from Western Washington to Mist Gas Field, Oregon
}

\author{
Final Report
}

\section{D.D. Hollis}

October 1992

Work Performed Under Contract No.: DE-AC21-88MC24155

For

U.S. Department of Energy

Office of Fossil Energy

Morgantown Energy Technology Center

Morgantown, West Virginia

By

Geophysical Systems Corporation

Pasadena, California

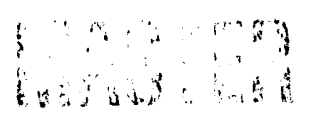


(II 


\title{
Deep Seismic Survey Extending from Western Washington to Mist Gas Field, Oregon
}

\section{Final Report}

D.D. Hollis

Work Performed Under Contract No.: DE-AC21-88MC24155

\author{
For \\ U.S. Department of Energy \\ Office of Fossil Energy \\ Morgantown Energy Technology Center \\ P.O. Box 880 \\ Morgantown, West Virginia 26507-0880 \\ By \\ Geophysical Systems Corporation \\ 3085 East Foothill Boulevard \\ Pasadena, California 91107-3151
}

October 1992 


\section{DISCLAIMER}

This report was prepared as an account of work sponsored by an agency of the United States Government. Neither the United States Government nor any agency thereof, nor any of their employees, makes any warranty, express or implied, or assumes any legal liability or responsibility for the accuracy, completeness, or usefulness of any information, apparatus, product, or process disclosed, or represents that its use would not infringe privately owned rights. Reference herein to any specific commercial product, process, or service by trade name, trademark, manıfacturer, or otherwise does not necessarily constitute or imply its endorsement, recommendation, or favoring by the United States Government or any agency thereof. The views and opinions of authors expressed herein do not necessarily state or reflect those of the United States Goveinment or any agency thereof.

This report has been reproduced directly from the best available copy.

Available to DOE and DOE contractors from the Office of Scientific and Technical Information, P.U. Box 62, Oak Ridge, TN 37831 ; prices available at (615) 576-8401.

Available to the public from the National Technical Information Service, U.S. Department of Commerce, 5285 Port Royal Rd., Springfield, VA 22161; phone orders accepted at (703) 487-4650. 


\begin{abstract}
Between October 1988 and September 1990, approximately 217 kilometers of vibroseis seismic reflection data was collected in Washington State. In particular, the profiles were placed to image a body of low resistivity rocks postulated to be marine sediments which were delineated by Stanley using magnetotelluric methods. The low resistivity rocks are known as the Southwestern Washington Cascaid indnctor (SVCC).

The profile data was processed using standard reflection seismic methods and also state-of-the-art data enhancing and 3-D reconstruction methods. Along with the refiection data, several dynamite refraction profiles and 3 component data were collected. The reflection and refraction data has been Intexpreted by Lawrence Berkeley I.aboratory, Morgantown Energy Technology Center and the University of West Virginia. Results of the Lawrence Berkeley and University of West Virginia work are presented in a separate reports.

Thio rejurt summartzes the data acquisttion and processing portions of the project.
\end{abstract}




\section{Preface}

This report describes the state of the art seismic reflection profi.e collected over the Southwestern Washington Cascades Conductor in Washington state. It summarlizes the data collection activities of the survey. Results of the interpretation of the survey can be found in reports by lawrence Berkeley Laboratory and Morgantown Energy Technology Center. 
The authors wish to acknowledge those that have contributed to this projeci.

United States Geological Survey Dal Stanley

Department of Energy - Morgantown Energy Technology Center

B111. Gw1111am

Gary Latham

Charles Byrer

Steve Krehble1

Mary Rafalowski-Guide

Thomas Muoz

Laura Bryant

University of West Virginia

Tom Wilson

GeoTrace Technology

John Contino

Golden Geophysical

Rob Windels

Rick Steineck

I awence Berkeley Jaboratory

Ixtic Majer

Tom Daly

Rocky Mountain Permit: Service

Jim Quintinej1a

Geophysica 1 Systems Corporation

Samuel Allen

Lincoln Martin

Dan Scanlan

Carl Ryals

Jesus Galindo

Field Party 128

Geosystems Pty Ltd

Steve Tobin 
Table of Contents

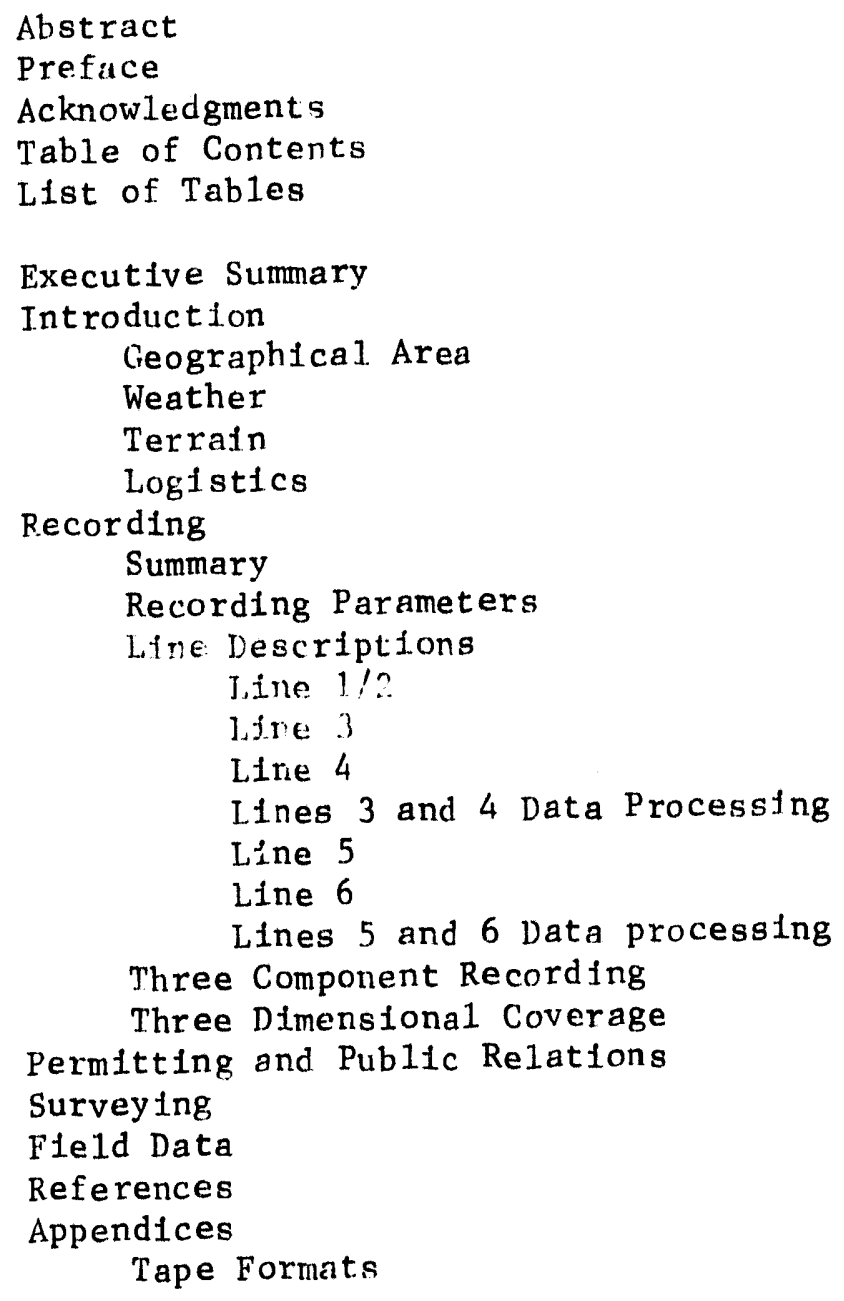

Tape Formats 


\section{list of Tables}

1. Data Acqufsttion Parameters

2. Summary of Lines

3. Processing Sequence for Lines $1 / 2,3$, and 4 .

4. Processing Sequence for Line 1 West and line 1 East

5. Processing Sequence for Lines 5 , and 6 . 
The purpose of this project was to acquire, process, and interprot sotamis reflection and refraction data over the Southwestern Washington (ascitit. Conductor fin washington State. The profect was broken up into three portions each performed by a different contractor: project management and data acquistiton was performed hy Geophysical Systems Corporation; data processing was perfortned by Golden Geophysical for Lines 1, 2, 3, and 4 and by GeoTrace Technologtes for Lines 5 and 6; finally, data interpretation by Lawrence Berkeley Laboratory (LBL).

This report documents the data acquisition and data processing portions of this project. Information regrading the data interpretat wh w rton of this profect can be found in IBL's final report, "Sefsmic Imaging of the SWCC". 


\section{Introduction}

A deep crustal selsmic survey program was conducted in southwestern Washington State was carried out over three fleld seasons between October, 1988, and September, 1990, by Party 128 of Geophysfcal Systems Corporetion for the United States Department of Energy, Morgantown Energy Technolngy Center, Morgantown, West Virginfa.

\section{Geographic Area}

The study area is located in lewts, Thus ston and Pferce counties in the State of Washington.

\section{Weather}

Weather conditions ranged from fair and warm to rainy and cool. The data was collected over three fleld seasons during the summer or fall so as to minimize operational delays and hazards associated with wet weather.

\section{Terrain}

The survey area is located in the southern part of the Cascade range. The survey transverse was restricted to highways and logging roads for ease of operations and access. The terrain along the line ranges from flat to mountainous.

\section{Logistics}

The crew was accommodated in the cfty of Morton which is approximately in the center of the study area.

\section{Line Descriptions}

In a11, six reflection lines were recorded. Table 2 summarfies each line. Recording Parameters

Parameters used for the data recording are listed in Tabje 1.

Lines 1 and 2

Line 1 follows Highway 12 starting at Mossyrock, heads east and ends just west of Morton. Along several portions of the line vibrator sweeps were tested. 


\section{Table 1 - Data Acquisition Parameters}

Recording Instrument

Number of Active Channels Spread Geometry Offset Range

Fold

Receiver Interval

Geophone Type

Geophone Array

Energy Source:

Number of Vibator:

Vibrator Type

Vibrator electronics

Vibrator Array

Vibrator Interval

Sweep Type

Number of Sweeps per VP

Sweep Length

Tota1 Listen Time

Correlated Output

Sample Interval
GEOCOR IV 1,024-channel data acquisition and field processing system with expanded memories.

1,024

Split Spread

$10,240-0-10,240$ meters

256

30 meters (Line 1 only)

20 meters (Lines 2 thru 6)

Mark Product L-21A $10 \mathrm{~Hz}$

6 phones over the group array

Vibroseis

5

Litton Mode1 311 Truck-mounted units (27,000 Ibs peak force)

Pelton Advance I Model 5 with

force control and RAM options

Bumper-to-Bumper, Stationary

(approximately 40 meters from first pad

to last pad)

60 meters (Line 1 only)

40 meters (Lines 2 thru 6)

VARISWEEP ${ }^{\text {TM }}$ composed of 6 linear

subsweeps as follows:

$$
\begin{array}{rl}
24-9 \mathrm{~Hz} & 27-9 \mathrm{~Hz} \\
30-10 \mathrm{~Hz} & 33-11 \mathrm{~Hz} \\
36-12 \mathrm{~Hz} & 39-13 \mathrm{~Hz}
\end{array}
$$

18 ( $3 \times$ Subsweep Set)

15 seconds

30 seconds

15 seconds

\begin{tabular}{|c|c|c|c|c|}
\hline Line No. & Station 非s & Length $(\mathrm{km})$ & Start Date & Finish Date \\
\hline 1 & $101-851$ & 22.500 & $10 / 20 / 88$ & $10 / 27 / 88$ \\
\hline 2 & $2513-3642$ & 22.580 & $10 / 29 / 88$ & $11 / 13 / 88$ \\
\hline 3 & $3001-5236$ & 44.700 & $7 / 25 / 89$ & $8 / 13 / 89$ \\
\hline 4 & $4001-7316$ & 66.300 & $8 / 16 / 89$ & $9 / 09 / 89$ \\
\hline 5 & $962-2957$ & 39.900 & $8 / 14 / 90$ & $8 / 29 / 90$ \\
\hline 6 & $1001-3550$ & 50.980 & $9 / 01 / 90$ & $9 / 22 / 90$ \\
\hline
\end{tabular}

4 milliseconds

Table 2 - Summary of Lines 
Line 1 used an offset range of 15,360-0 - 15,360 meters. Initial field data processing showed first break energy and observable reflection energy dying out around 10,000 meters. After briefly acquiring data with an reduced number of chanriels to limit the far offsets, a drecision was made to change the receiver geometry to $10,240-0-10,240$ meters by picking up and relaying the recording spread of 1,024 channels at a 20 meter group interval. instead of the 30 meter group interval. The last source point on Line 1 was \#851 and the active spread was from station \#526 to station 非175. Using station $\$ 851$ as a center point the spread was changed and station \#851 then became station $\#_{2513}$ on Line 2. The first active channel on Line 2 for VP \#2513 was \#2001 whlch was roughly in the same location as station \#50? on Line 1. The last active chantel on Line 2 for VP \#2513 was \#3cic which was rough1y in the same location as station \#1192 on Line 1.

Lines 1 and 2 are described as two separate 1 ines in the raw data set, but were processed by Golden Geophystcal as nne line which has been named 'Line $1 / 2^{\prime}$ and data from both lines are contained some special processed versions known as 'Line $1 \mathrm{~W}$ ' and 'Line $1 \mathrm{~F}$ '.

Line 2 continued along Highway 12 to east unt 11 the town of Randle.

Lines 1 and 2 were sent to Golden Geophysical for processing. The processing flow for these lines are shown in Table 3.

Table 3 - Processing Sequence for Line $1 / 2$

Reformat

Crooked Line Geometry Description and Application

Refraction Statics Calculation

Refraction Statics and Normal Moveout Corrections

Shot Summing

Spherical. Divergence and Inelastic Attenuation Corrections

Deconvolution

Datum Statics

CMP Sort

Data Set Merge

Velocity Analysis

Surface Consistent Residual Statics

Velocity Analysis

Surface Consistent Residual staties

howal lownout Corrections

First Break Suppression

Time Variant Scaling

Datum Statics Application

CMP. Stack

F-X Spatial Deconvolution

Band Pass Filter

Trace Balance

Phase Correction to Zero Phase 
Although Lines 1 and 2 are Identified as separate line, they, along with Line 3 which was acquired during the next fleld season, make up a continuous profile along Highway 12 from Mossyrock to 7 miles pass Packwood. Line 1 has a CMP interval of 15 meters and Line 2 has a CMP interval of 10 meters. To merge the two lines adjacent channels were summed with static and dynamic corrections applifed resulting $2 \mathrm{n} z 30$ meter CMP interval for both lines.

After the final sections vere completed, two portions of Line $1 / 2$ were selected for more detalled processing so as to determined procedures to improve data quality. These portions were designated as Line l. West and Line 1 East. Table 4 shows the processing flow for these sections.

Table 4 - Processing Sequence for Line 1 West and Line 1 East

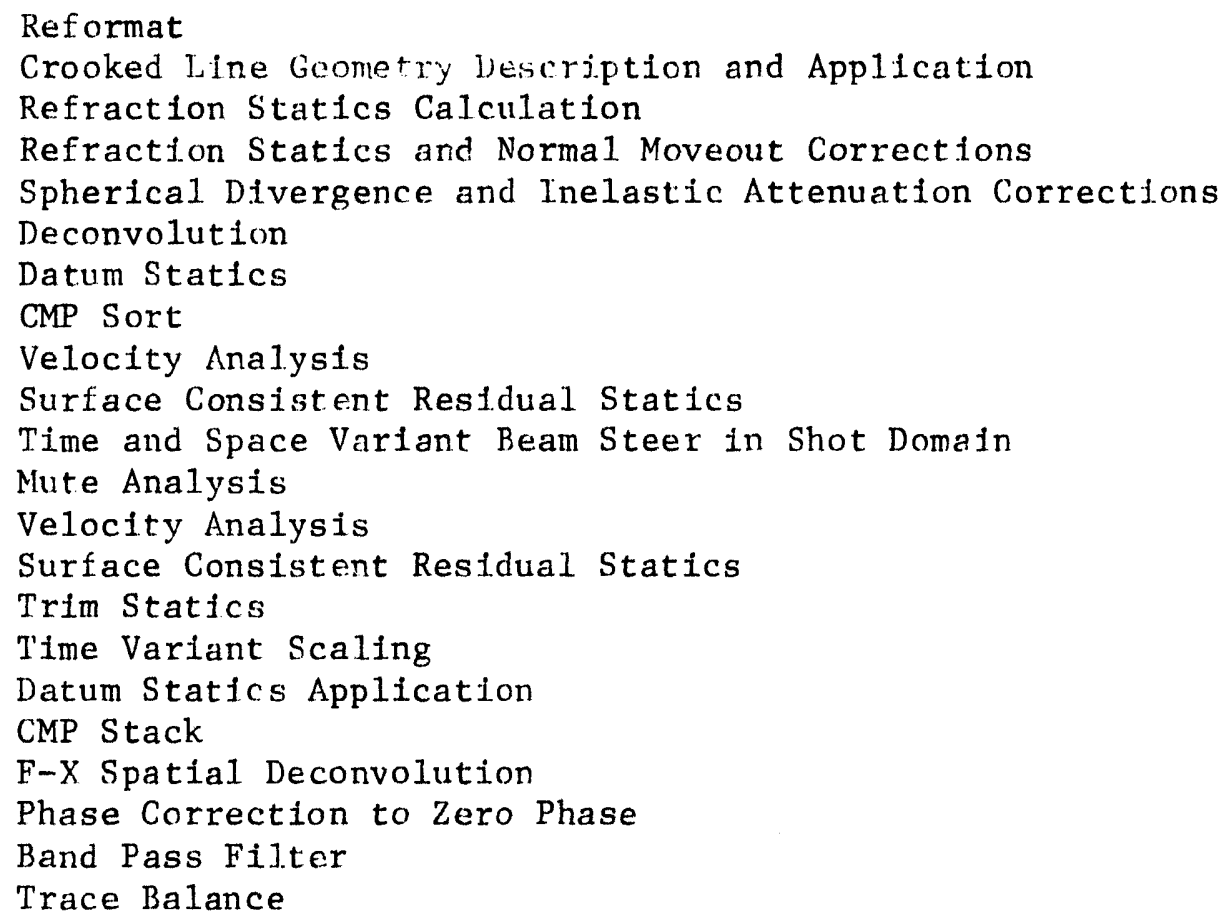

\section{Line 3}

Based on the results of data processing after the first field season, the decision was made to extend Line $1 / 2$ to the east along Highway 12 . Originally, Line $1 / 2$ terminated at the town of Randle. In order to maintain consistent fold the beginning of Line 3 was started back to the west one-half spread length or approximately 5 kilometers from the town of Randle. Line 3 continued east along Highway 12 and terminated about 7 miles east of Fackwood near the junction of Highway 12 and 123 . 
$1,1 i_{i} t_{-} 4$

line 4 started about 8 kilometers southeast of the town of Morton where the Cosmos Road terminates at the Cowlitz River. The line proceeds northwest up Cosmos Road then heads west on Highway 12. At Fern Gap the Line proceeds along 01d Railroad Grade Road skirting the town of Morton to the north and then proceeds west on Highway 508 and ends near the town of Alpha.

The receiver spread at the beginning of Line 4 was also used for refraction profiles. The source for the refraction profiles was 60 to 90 pounds of Jyamite in a single hole per shot ranging from 40 to 68 feet in depth.

i.ne 3 ard 4 data processing

Both Lines 3 and 4 along with the refraction profiles on Line 4 were collected during the second field season in 1990. The reflection data was processed by Golden Geophysical using the same processing flow developed from the previous year's work. The refraction data was sent to Lawrence Berkeley Laboratory and to Dr. Tom Wilson of the Untversity of West Virginfa for analysis and interpretation.

Line 5

Line 5 starts about 10 kilometers west of the town of Morton on Highway 12 . The line proceeds east then turris to the wis cround the restern side of the town of Morton were it joins Higliway 7 and heads north finally ending at the town of Elbe on the Nisqually River.

The first 10 kilometers of Line 5 coincldes with Line 1 . This duplicated segment allowed another look at this segment of Line $1 / 2$ using the second set of data acquisition parameter used for Line 2. Also, this additional spread allowed fold to build so the tie points between Line 5 and Line $1 / 2$. were at full fold.

The flrst 1024 stations of Line 5 were used for a refraction spread. Refraction profile: wimil cynamite ard vibroseis sources were acquired.

Line 6

Line 6 started at the Weyerhauser Operations Center near the town of Rafnier and proceeded east crossing the Alder Lake Dan then joined Highway 708 east through the town of Elbe were it intersected Line 5 and ended a the entrance to Mount Rainier National Park.

\section{Lines 5 and 6 Data Processing}

Line 5 and 6 were sent to GeoTrace Technologies in Lenver for data processing. Based on the previous flows and testing performed on Line 5, lead to revision of the prevfous processing flow. This data processing, fin is shown in Table 5. The refraction data was sent to Lawence E' luje:" Laboratory and to Dr. Tom Wilson of the University of West Virginia for analysis and interpretation. 
Table 5 - Processing Sequence for Lines 5 and 6

\author{
Recording Galn Removal \\ Geometry Definition \\ Trace Editing \\ Refraction Statics \\ Surface Conslstent Deconvolution \\ Automatic Gain Control \\ Trace Balance \\ Time Variant Spectral Balance \\ Velocity Analysis \\ Surface Consistent Residual Statics \\ Velocity Analysis \\ Surface Consistent Residual Statfo: \\ Normal dioveoui \\ $X-T$ Spatial Filter in Shot Domain \\ CMP Gather \\ Trim Statics \\ Normal Moveout Stretch Mute \\ CMP Stack \\ Finite Difference Wave Equation Migration \\ $\mathrm{X}-\mathrm{T}$ Noise Reduction Filter \\ Bandpass Filter \\ Trace Balance
}

Lines 5 and 6 Three-Component Recording

An experiment was piggy-backed onto the reflection data recording on both Lines 5 and 6 . 3-component geophones were placed every 300 channels along the recording spread. The 3-componin yeophone replaced three adjacent channel, each channel recording a different component. The first starion on Line 5 to have a 3-component geophone was 1001. The components were placed on adjacent channels in the following order: vertical, north, then east. Because of the crooked nature of the recording spread, lateral and transverse polarizations would have been difficult, if not impossible to determine, so horizontal polarizations were aligned north-south and east-west. Therefore, station 1001 was the vertical component, station 非 1002 was the north-snibl conponent, and station \#1003 was the east-west component, and so on.

Three Dimensional Coverage

Due to the mountainous terrain of the study area the selsmic lines were placed along roads and highways. The crookedness of the seismic ines meant that source-to-receiver midpoints are scattered around the seismic line. This scattering provides three dimensional information of the subsurface. Three of the seismlc lines $(1 / 2,4$, and 5) passed through the town of Morton anci culictdentally had major bends in the seismic lines as they pass through the town. This resulted in an area around Morton that contain a large amount of scattered midpoints. GeoTrace used these scattered midpoints to produce additional section reconstructions of the subsurface. 
All permitting was done by Jim Quintinella of Rocky Mountain Permit Service of Monument, Colorado. Public relations were good with the local residents and authorities.

\section{Surveying}

Surveying was performed using a surveyor's chain to measure and cieploy the statjon markers. Northing, easting and elevetion werc masured using theodolite and EDM equipment. Raw data was recorded by hand notes and then processed on a fleld computer. Processed survey data is avallable in printout form and on 9 track tape. The data format for the 9 track tape is shown in the appendix.

\section{Fleld Data}

The recording system demultiplexs, correlates and composites the data before recording the data to 9 track tape. To reduce the volume of tapes for storage the data was copled from 9 track tape to $8 \mathrm{~mm}$ tape cartridge.

\section{References}

Daly, T.M., Majer, F.J., 402, Selsmtc Imaging of the SWCC, Lawrence Berkeley I,aboratory Report, LBL-31982, UC-132. 
Append 1x

Tape Formats

$-17-$ 
Field data is recorded on IBM compatible $\frac{1}{2}$ inch, 9 track tape in demultiplexed format at either 800 or 1600 bits-per-inch density. Each tape reel is divided into trace data blocks each contalning a trace identiflcation header and data values from one channel (Fig. 1). Each trace data block is separated from the next by a .6 inch interblock gap (IBG). Data values are recorded in two's complement notation with 16 bits per sample standard (recording 1 or 8 bits per sample is avallable as a non-standard option).

Two trace data block formats are avallable:

Irace Data Block - 4 word Trace Identification Header (F1g. 2)

Format 1

Trace Data Block - 32 word Trace Identification Header (F1g. 3) Format 12

Trace data block Format 2 contains more header information and is standard. TRACE HEADER ITEM DEFINITIONS

File number is the eqquential number assigned to each record (or file) on a sagnetic tape. Each line of recelvers generates one record at each source point. A record way contain from one to 1024 traces. The file numbering begins at one for the first record on the first tape and continues sequentially through all the tapes for the IIne.

Trace Number is the sequential number, beginning at 1 , assigned to each trace collected at a source point.

Source Point Number represents the actual number assigned to each source point by the surveyor.

Port/Channel Code is a code identifying the input port and channel used to collect each trace. The most significant 6 bits represent the port $(0-15)$ and the least significant 10 bits represent the channel $(0-1023)$.

Source Line Name is the alphabetic or numeric identification of the line of source points.

Receiver Line Nare is the alphabetic or numeric identification of the line of receivers.

Receiver Number represents the actual nlimber assidned to each receiver location by the surveyor.
Format

16 bit two's complement

Limits

15032767

16 bit two's

1 to 1024

complezent

16 bit two's

complement

-32767 to

32767

$6 \mathrm{bit} / 10$ bit

$0-15 / 0-1023$

two's complement

6 ASCII characters

left justified

6 ASCII characters

left justified

16 bit two's -32767 to 3276 
FIELD TAPE FORMAT

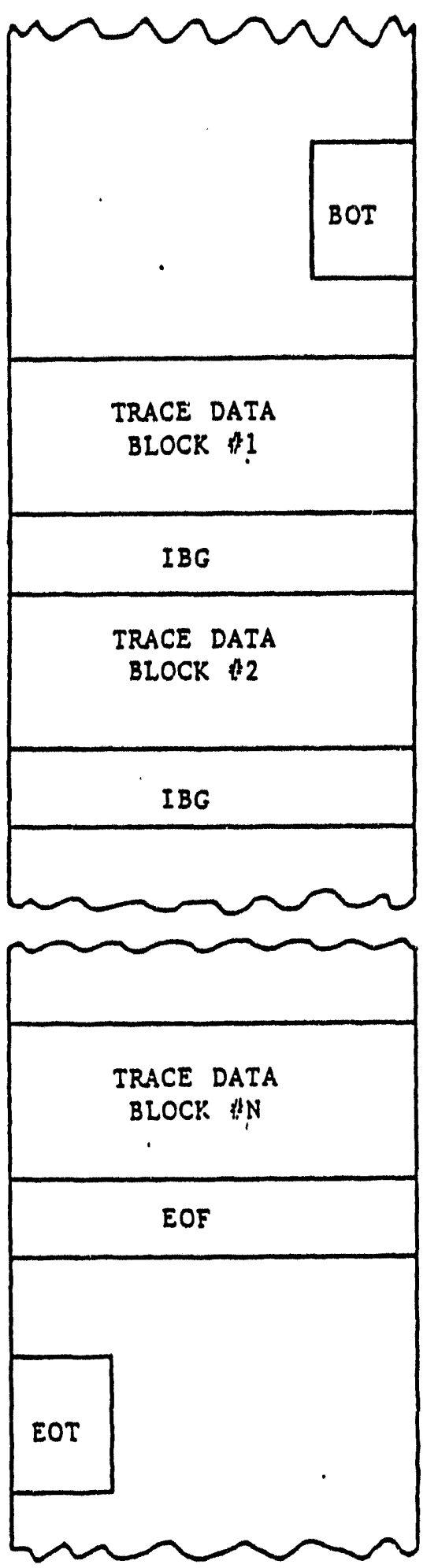

FIG. 1 


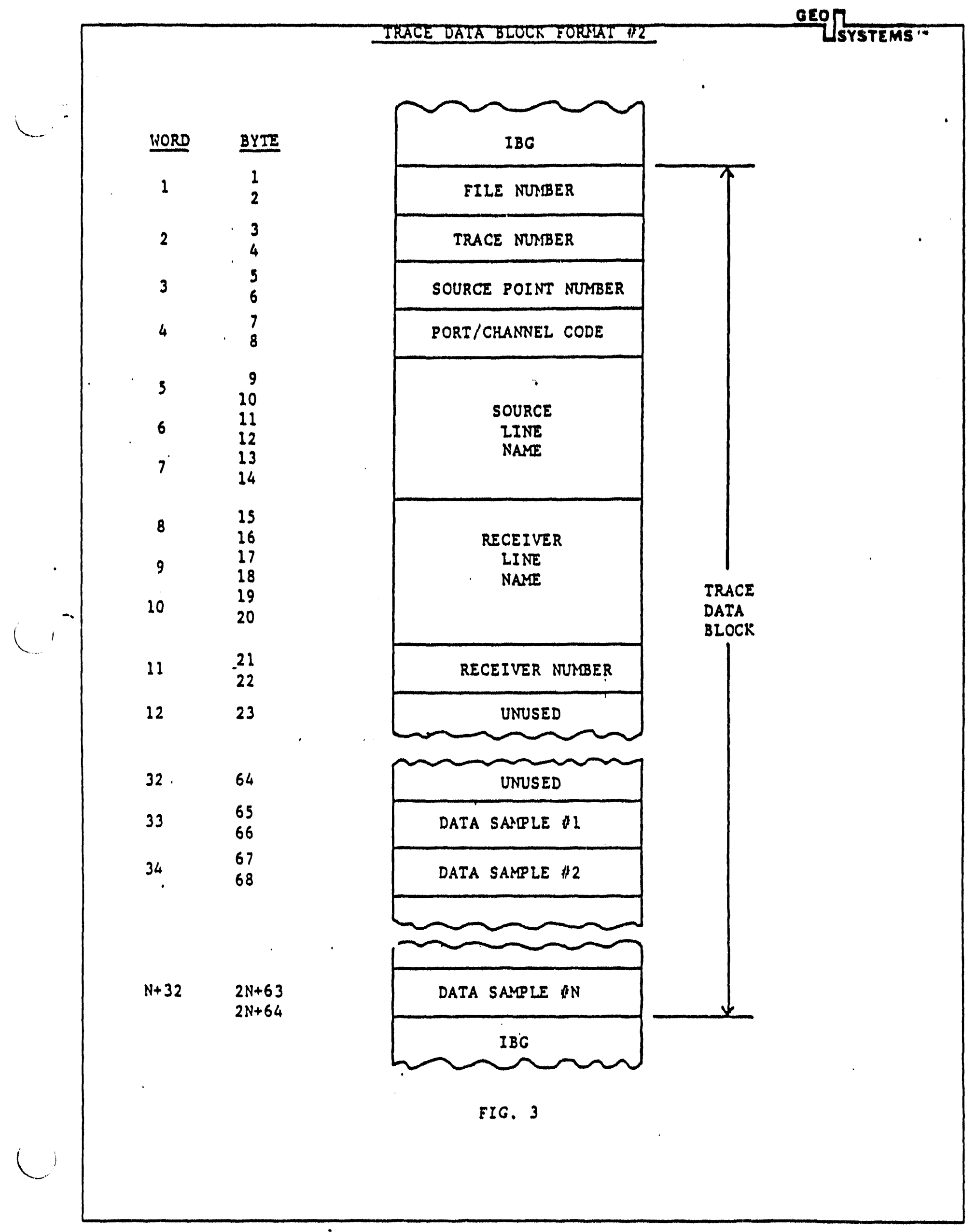




\section{GEOCOR IV}

\section{LOG TAPE FORMAT}

Al1 acquistion parameters and 108 entries recorded in the GEOCOR IV Acquisition Log may also be recorded on magnetic tape for 1nput to subsequent data processing steps. Each line of text written in the 108 may be recorded as a 65-word block on tape. The format of aach text block is described in Figure 2.

Information describing each source point as it is acquired 1s also racorded in a second format (f1gures 3, 4, 5). Each source point generates one block of information which contains one section describing the source location and identification and sixteen sections describing the recelver conflgurations. The source point blocks are 501 words long with the source section occupylng words 2-101 and the recelver sections occupying words 102-501. One recelver section is filled in for each independent line of ective recelvers. An 1llustration of the total log tape is shown in flgure 1.

The information is recorded on IBM comparible, inch, 9-track magnetic tape at elther 800 or 1600 bits-per-inch density. Each block of information is separated from the next by a .6 Inch interblock gap (IBG). The source point blocks are written on tape in triplicate to insure that they can be read correctly. Each source point block contalns a checksum word to perwit detection of Incorrect reads. 
Source Point Number - the number assigned to the actual ground location of each shot or vibrator point.

Source Line Nawe - the alphabetic or numeric Identiflcation of the line of source points.

Number of Recelver Lines - the number of independnit lines of recelvers active during date acquisielon.

Checksum - the exclusive-or checksum. of all the date within the block.

File Number - the number assigned to ench group of traces generated by a line of recelvers. The flle numbers are sequential on tape.

Receiver line Name - the alphabec1c or numeric idenefflcation of the line of receivers.

Reel Identiflcation - the alphabetic or numeric identification of the magnetic tape reel.

Number of First Active Trace - the number of the flrst trace containing seismic daca.

Receiver Number of First Active Trace - the number assigned to the recelver location of the flist active trace.

Number of Last Active Trace - the number of the last trace containing seisaic data.

Receiver Number of Last Active Trace - the number assigned to the receiver location of the last active trace.

Number of Traces/File - the number of active and dumy traces within each file on tape. The number of traces/file does not change withio a line.

Block Identification Code - the number which 1dentifies the type of block. 0 - Source Point Block

1. Text Block

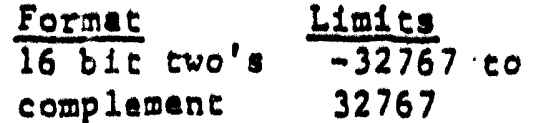

6 ASCII characters left Justifled

16 b1t two's it to 16 complement

16 bit two's -32768 to couplewent 32767

16 b1t two' 1 to 32767 complement

6 ASCII characters left Justifled

10 ASCII characters left fustefied

16 b1t two's 1 to 1025 complement

16 b1t two's -32767 to complement $\quad 32767$

16 b1t two's 1 to 1025 complement

16 b1e two's -32767 to cceplement 32767

16 bit two's I to 1025 complement

16 b1t two's 0 to 1 cceplement 


\section{LOG TAPE}

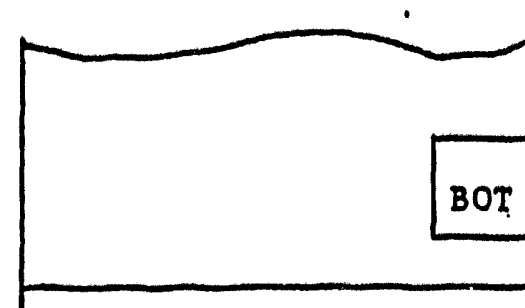

TEXT BLOCX

TEXT BLOCK

TEXT BLOCK

SOURCE POINT BLOCR II COPY 1

SOURCE POINT BLOCK I COPY 2

SOURCE POINT BLOCK 1 COPY 3

TEXT BLOCX

TEXT BLOCR

TEXI BLOCR

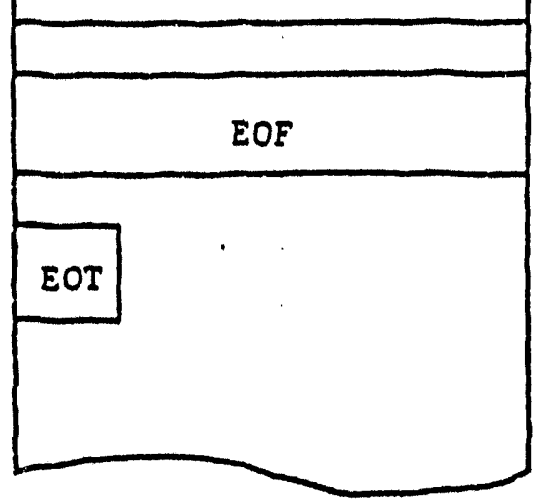


TEXI BLOCK

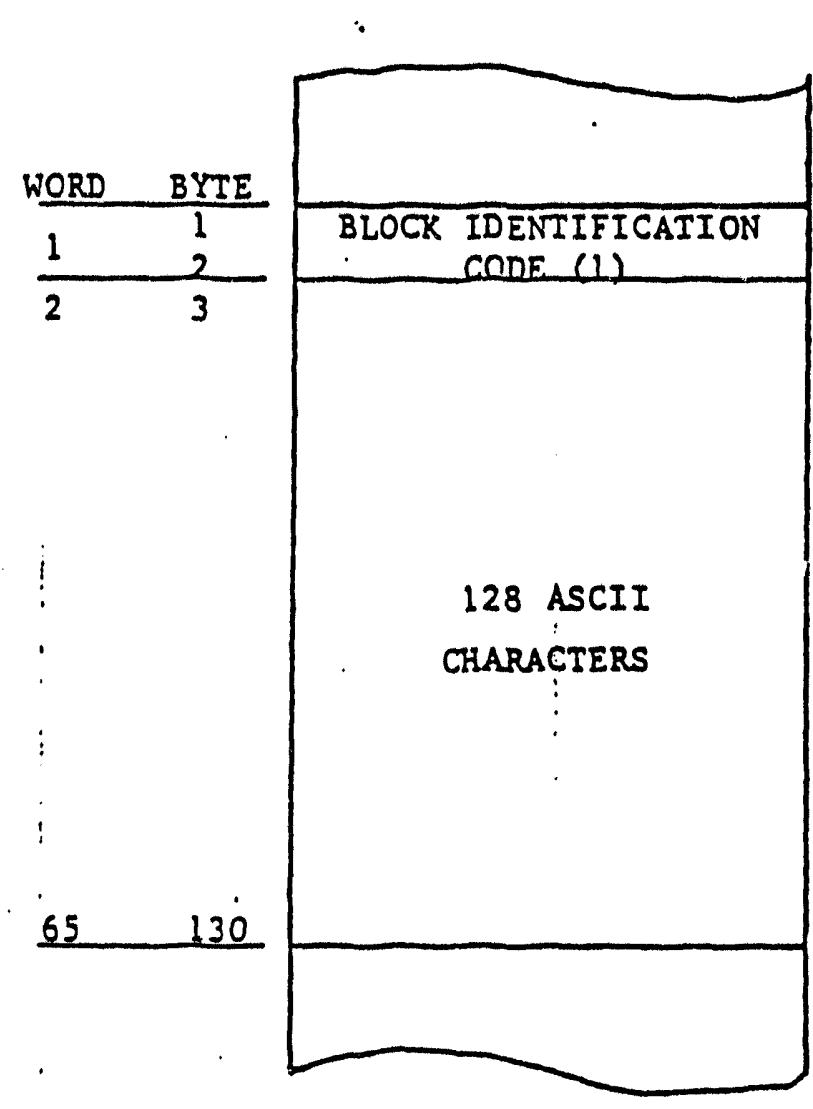

F18. 2 


\section{SOURCE POINT BLOCK}

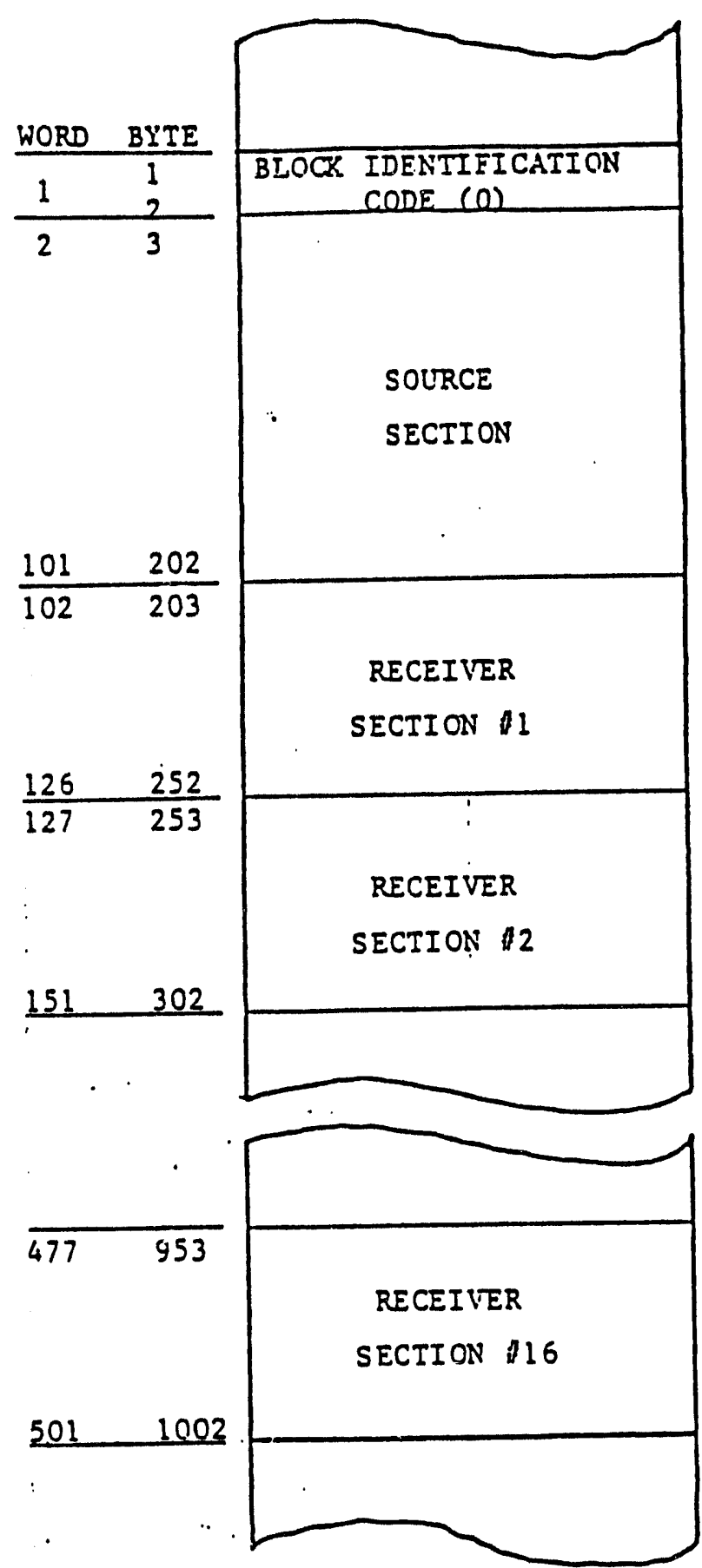

Fig. 3 
SOURCE SECTION

OF SOURCE POINT BLOCK

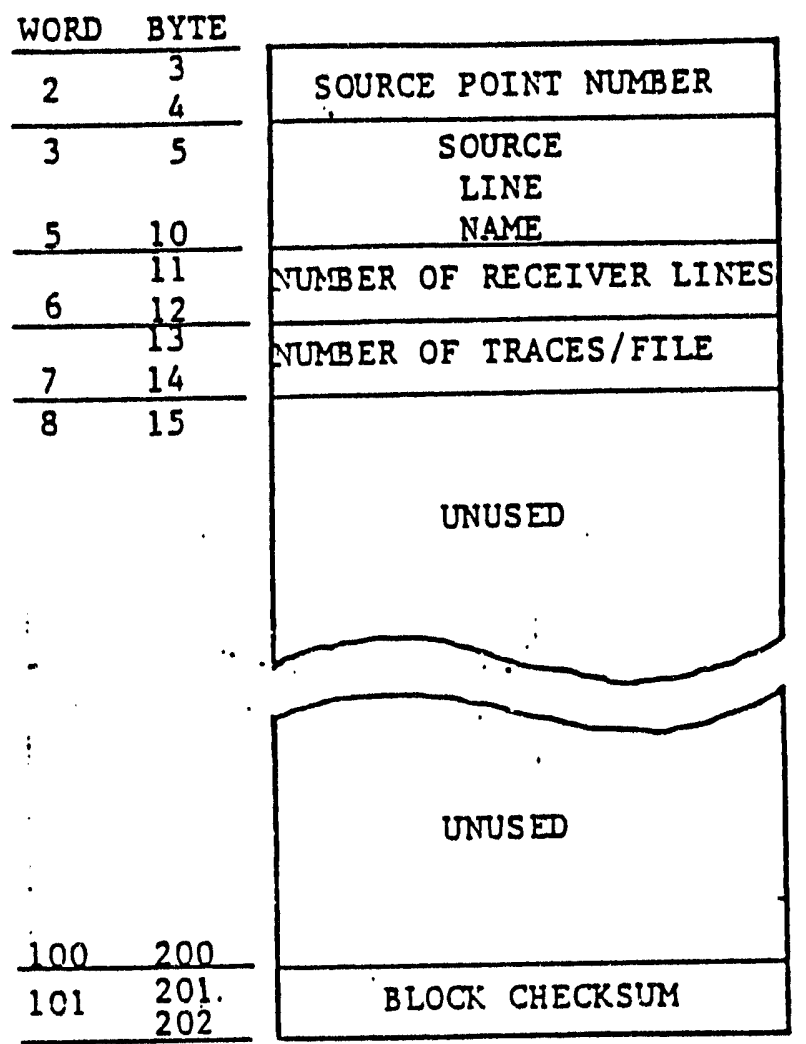

F18. 4 
$\therefore$.

RECEIVER SECTION \#1

OF SOURCE POINT BLOCX

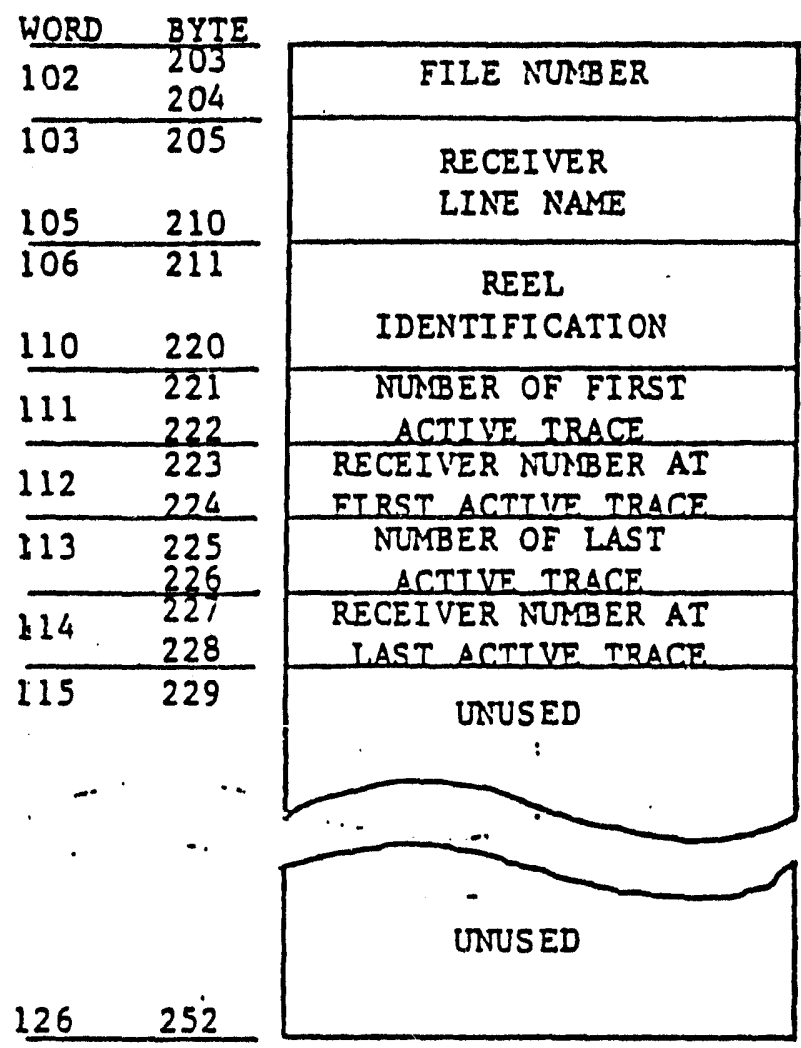

Fig. 5 
GEOOOR IV

Coordinate Tape Fonmat

The GDOCOR IV System records gecphysical survey information on recrnetic tape in a blocked, gapped format which is fully IBM compatible. For each source point and recelver location associated with the survey, $X, Y$, and $Z$ cooriinate, resicual static correction, latitucie and longitude information is included. This information is recoroed in data blocks which are followed on the coordinate tape by edit blocks which include receiver edit information for each source point.

The tape is an IBM-campatible 9-track-magnetic. tape that is recorded at either 800 or 1600 bits-per-inch (BPI). Tape cocies consist of 16-bit words which include a sign bit and 15 data bits. The data bits are recorded in a straight binary coce with a two's camplement neçative number representation. The sign bit of the least significant word of two word values is always. set to zero.

The coordinate tape is written with three identical copies of each block. Each block is separated fran the next block by a .6 inch interblock gap (IBG). Deta blocks contain 2002 words each and edit blocks contain 1040 words each. (Fig. 1)

Each data block contains a block mmber (word 1), 100 20-word records (words 2-2001) and a checksum (word 2002). (Fig. 2) Each 20-word record is associated with a source point of receiver location. Latitude and longitude are expressed in hundredths of a second. . as 32-bit integer values. (Fig. 3)

Each edit block contains a block number (word 1), the source point number to witich the edits apply (word 2), the number of receiver ecits included in the block (word 3), spare words (words 4-15), recelver edits (words 16-1039) and a check:sum (word 1040). (Fig. 4)

The first $n$ blocks on the coordinate tape contain source point location data and are numbered consecutively from 1 to $n$. These are followed by $m$ blocks containing receiver location data numbered from 1 to $\mathrm{m}$. An all-zero record indicates the termination of data within a block, and the remaincer of the records in that block will also be all-zero. These data blocks are followed by $p$ eait blocks numbered consecutively fram 1 to $p$. There is one 1040-word edit block for each source point described in the first $n$. data blocks. 


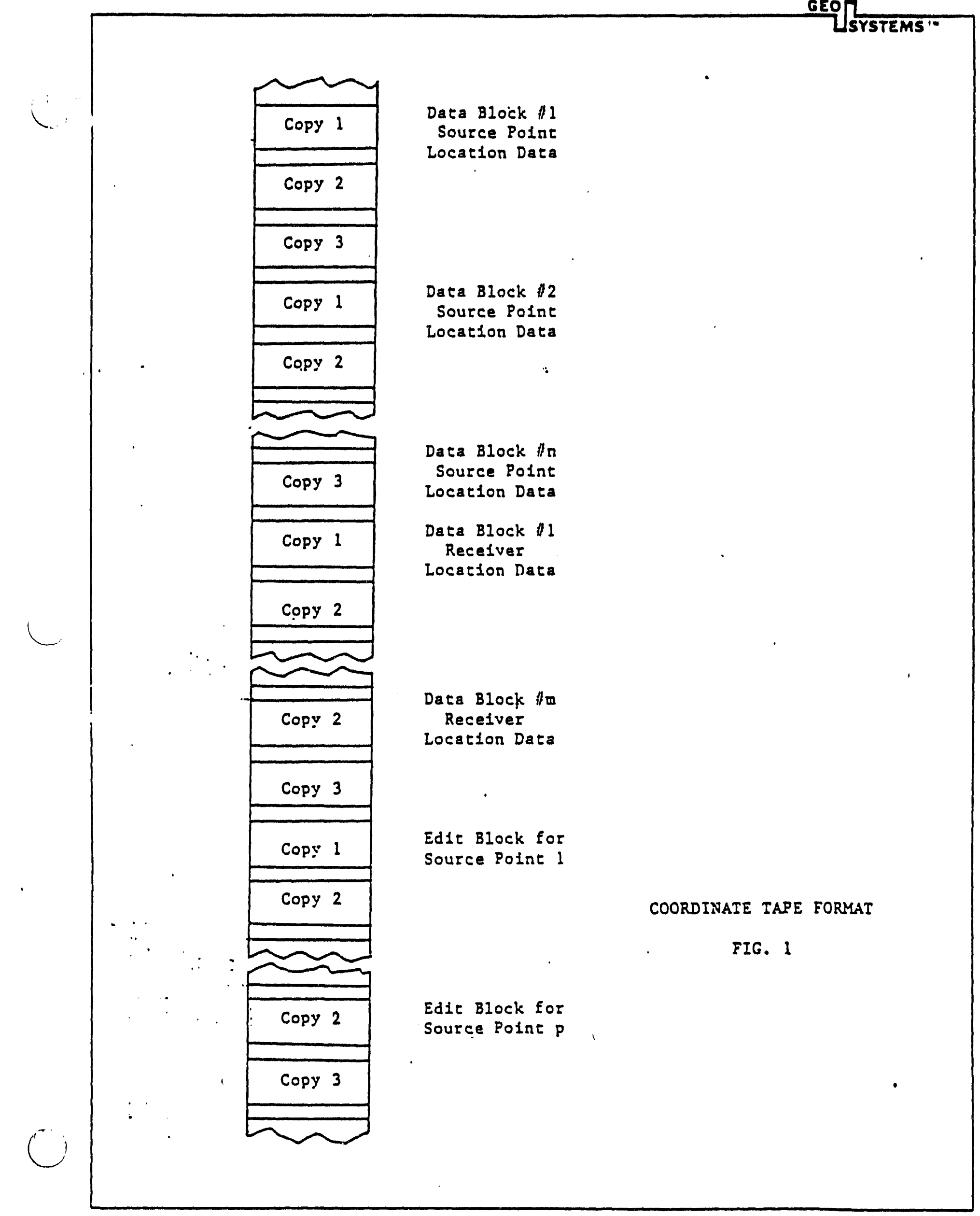




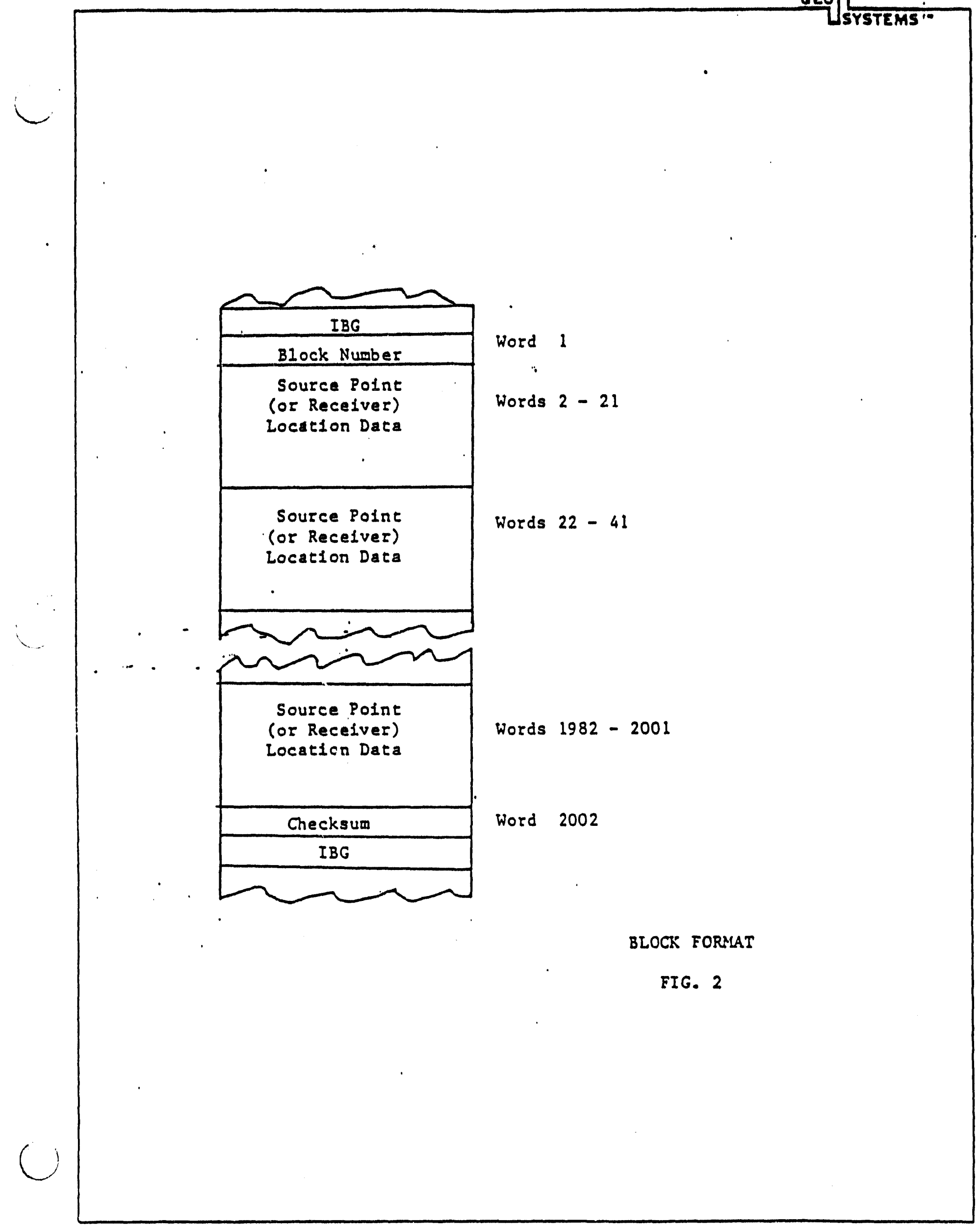


Hords $1-3$ Name ( 6 Ascil character left justified)

Source or Receiver

2-word $X$ coordinate

Hord 4

Hiords 5, 6

2-word $Y$ coordinate

liords 7,8

1-word $z$ coordinate

liord 9

2-word packed latitude

fiords 10,11

Words 12,13

Word 14

Available for

additional data

Niords $15-20$

DATA RECORD FORMAT

FIG. 3 

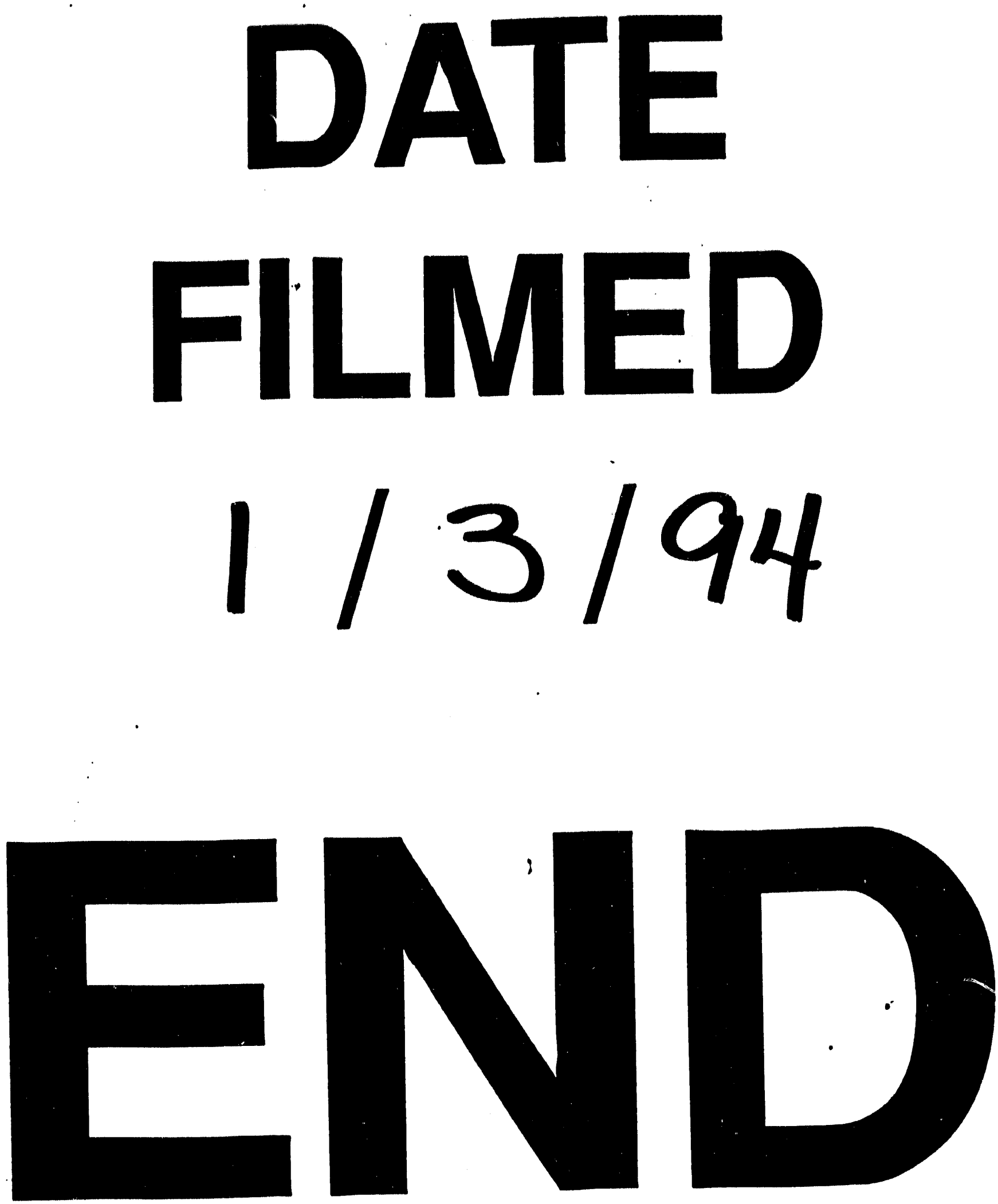
